\title{
บusisersaly
}

\section{A prospective randomized trial of chemonucleolysis and conventional disc surgery in single level lumbar disc herniation}

Muralikuttan, K. P., Hamilton, A., Kernohan, W. G., Mollan, R. A., \& Adair, I. V. (1992). A prospective randomized trial of chemonucleolysis and conventional disc surgery in single level lumbar disc herniation. SPINE, 17(4), 381-387. https://doi.org/10.1097/00007632-199204000-00001

Link to publication record in Ulster University Research Portal

Published in:

SPINE

Publication Status:

Published (in print/issue): 01/04/1992

DOI:

10.1097/00007632-199204000-00001

Document Version

Publisher's PDF, also known as Version of record

\section{General rights}

Copyright for the publications made accessible via Ulster University's Research Portal is retained by the author(s) and / or other copyright owners and it is a condition of accessing these publications that users recognise and abide by the legal requirements associated with these rights.

\section{Take down policy}

The Research Portal is Ulster University's institutional repository that provides access to Ulster's research outputs. Every effort has been made to ensure that content in the Research Portal does not infringe any person's rights, or applicable UK laws. If you discover content in the Research Portal that you believe breaches copyright or violates any law, please contact pure-support@ulster.ac.uk. 


\title{
A Prospective Randomized Trial of Chemonucleolysis and Conventional Disc Surgery in Single Level Lumbar Disc Herniation
}

\author{
K. P. Muralikuttan, FRCS, MMedSc, A. Hamilton, MD, FRCS, W. G. Kernohan, PhD, \\ R. A. B. Mollan, MD, FRCS, and I. V. Adair, FRCS
}

\begin{abstract}
The role of chemonucleolysis as an alternative to disc surgery is still disputed. The authors conducted a prospective randomized controlled trial of chemonucleolysis and conventional disc surgery involving 92 patients with L4-5 or L5-S1 disc herniation who failed to respond to conservative treatment. There were 46 patients in each group, matched for demographic, clinical characteristics, and co-interventions. Independent examiners assessed patients before treatment, at 6 weeks after, 3 months after, and 1 year after treatment. A comprehensive method of outcome assessment involving physiological outcome, functional outcome, cost outcome, and psychological outcome was employed. Nine chemonucleolysis patients and one disc surgery patient required additional surgery for failure of initial treatment $(P<0.02)$. The outcomes at 6 weeks and at 3 months were better in the surgical group, but at 1 year the differences were not significant. The authors conclude that chemonucleolysis as a minimally invasive technique produces inferior short-term results and offers no advantage over conventional discectomy. [Key words: Chemonucleolysis, disc surgery, cost]
\end{abstract}

Since the original description of lumbar disc prolapse by Mixter and Barr in 1934, the mainstay of treatment after failure of conservative measures has been surgical discectomy. ${ }^{16}$ The first alternative intervention to discectomy was described by Feffer who reported favorable results in $50 \%$ of cases after intradiscal injection of hydrocortisone. ${ }^{6}$ Percutaneous enzymatic intervertebral disc chemolysis or chemonucleolysis using the enzyme chymopapain was first described by Lyman Smith in $1963 .{ }^{22}$ The efficacy of chemonucleolysis in the treatment of lumbar disc prolapse has been established in placebo controlled trials. ${ }^{7,9}$ However, the role of chemonucleolysis as an alternative to disc surgery is still disputed. $1,2,5,11,17,24,25,30,32,34$ There have been few random-

From the Department of Orthopaedic Surgery, Queen's University of Belfast, Musgrave Park Hospital, Belfast BT9 7JB.

Supported by a grant from the Medical Research Council.

Accepted for publication November 6, 1991. ized controlled comparisons between disc surgery and chemonucleolysis. ${ }^{2,5,25}$

The increasing trend toward minimally invasive surgery ${ }^{10,34}$ in an effort to minimize the surgical trauma and expedite rehabilitation has made the comparison more relevant. Two earlier controlled trials showed better results with disc surgery but did not have adequate statistical power to draw any firm conclusions. ${ }^{2,5}$ To date there had been only one acceptable prospective randomized study in terms of number of patients comparing chemonucleolysis with surgical discectomy, which suggested that the results at 1 year after surgery were not significantly different from those after chemonucleolysis. ${ }^{25}$ However, there was a significant number of failures after chemonucleolysis in the patients involved in this study. In most studies comparing chemonucleolysis and disc surgery, the outcome assessment depended largely on the subjective opinion of the surgeon and the patient and little attention was paid to the differences in quality of outcome during the first year after treatment. $1,2,17,18,24,30$

Most cost outcome studies have shown chemonucleolysis to be less expensive than laminectomy, ${ }^{8,17,20,21}$ but Norton reported it to be more expensive in compensation patients when the cost of reoperations for failed chemonucleolysis cases were also taken into account. ${ }^{19} \mathrm{Com}-$ pensation patients are those who at the time of treatment have a compensation claim filed against their employers or insurance company claiming that their disc prolapse occurred during work as a result of work or a work accident. Maroon et al. found microdiscectomy to be less expensive than chemonucleolysis even though the hospital stay was same for both groups during primary treatment. ${ }^{14}$ Other studies showed that chemonucleolysis reduced hospital stay. ${ }^{3,11,15}$ None of the controlled trials comparing surgery and chemonucleolysis used cost comparison as an outcome measure. ${ }^{2,5,25}$

Weber showed that the long-term outcome of treatment of disc prolapse by conservative and surgical methods was not significantly different. ${ }^{31}$ Moreover, most patients were not totally symptom-free after treatment. 
Long-term outcome after treatment of disc prolapse by conventional surgery has been shown to be slightly better than that of chemonucleolysis. ${ }^{24}$ Therefore, the relative difference in the quality of outcome during the first year after treatment should be a main parameter deciding the superiority of one type of treatment over the other. Because of the complexity of the factors influencing outcome after treatment of disc prolapse, assessment based on a narrow spectrum of measures is less reliable. This study employed a comprehensive assessment system that included measurement of back and leg pain, physical impairment, functional disability, and psychological scoring for anxiety and depression. ${ }^{13,26-29,35}$

\section{- Materials and Methods}

Subjects. All 92 patients included in this study were admitted to the Withers Orthopaedic Centre, Musgrave Park Hospital, Belfast, under care of 15 consultants, between June 1987 and December 1989. All patients had nerve root pain, with or without back pain. Patients considered for the study had failed to improve after a minimum of 4 weeks of conservative treatment including at least 2 weeks of complete bed rest. They had root pain and a radiologically consistent disc prolapse with signs of nerve root irritation, compression or both. Radiologic evidence was based on localized thecal indentation or decreased nerve root filling at the appropriate level on the radiculogram or localized disc bulge compromising the appropriate nerve root on the computed tomographic scan.

Patients with other lumbar spinal disease, rapidly progressive neurological deficit, cauda equina syndrome, allergy to papaya derivatives, history of severe anaphylactic reaction to other substances, radiographic evidence of sequestrated disc, diabetes mellitus, history of peripheral neuropathy, multiple disc herniations and disc herniations at levels other than L4-5 or L5-S1 were all excluded from the study. Patients with root symptoms for more than 2 years were excluded from the study. A history of accident at work or legal proceedings were not considered exclusion criteria but were noted. Ethical committee approval for the study was granted by the Queen's University of Belfast.

Evaluation of Subjects. The study was coordinated by a single research fellow (KPM) who was responsible for screening the patients for inclusion in the study and obtaining informed consent. The patient was allocated to a treatment group of either chemonucleolysis or surgery by a computer-generated randomization list. Clinical assessments were performed by one of six independent examiners (6 registrars/senior registrars) before treatment and at 6 weeks, 3 months, and 1 year after treatment. On each occasion, every effort was made to ensure that the same examiner evaluated the patient at each visit.

Inter-observer variability between examiners had previously been assessed by dividing them into three groups of two and asking each group to examine a selected number of back patients. Two examiners saw the same patient within 24 hours of each other. Agreement between the examiners was compared using Pearson's correlation. The variability was minimal among all the three groups.
A proforma, based on the low back pain assessment proforma proposed by Waddell, was used to record clinical data. ${ }^{26,29}$ This consisted of standardized items of information gleaned from the history and physical examination. The patients completed visual analog scales for pain and questionnaires pertaining to disability and psychological profile. Thus seven assessment scores were obtained at each patient visit: the physical impairment score, disability score, leg pain score, back pain score, psychological score, inappropriate symptom score, and inappropriate sign score.

Finally, the cost of treatment of 42 chemonucleolysis patients and 45 disc surgery patients were assessed at the end of the study, based on the 1990 figures for the costs of investigations, operating room time, operations, and hospital stay.

Randomization of Patients. The selected patients underwent a restricted randomization stratified for the level of disc prolapse as determined radiologically. This was to avoid potential differences in technical difficulty biasing the results of treatment.

Compliance. Approximately $40 \%$ of potential candidates were excluded from the trial because they were not prepared to contemplate randomization of their treatment.

Study Size. It was clear that disability measured on a scale of 1-9 would be the most likely parameter to show a difference in efficacy between the two procedures. The standard deviation of the mean disability was determined for a randomly selected group of 20 patients suffering from prolapsed intervertebral disc. Using this, it was calculated that a sample size of 45 patients in each group would be required to show a statistically significant difference in the smallest unit of the disability scale, that is, 1. Given the standard deviations for back pain and physical impairment in the sample, it would be expected that at least a difference of 20 units on the pain scale or $8 \%$ in the physical impairment scale would be required to achieve statistical significance.

Statistical Methods. Comparison of proportions were based on chi-square test with Yate's correction. When appropriate, Fisher's Exact test was used. Because most of the outcome variables showed skewed distribution, Mann-Whitney U test was used for comparison of differences between groups. Comparison of means within the groups with time were based on the Student $t$ test for paired differences. The reported significance levels for the Fisher exact test are one-sided whereas those for other tests are two-sided.

Procedure. Chemonucleolysis. Patients were medicated 1 hour before with $4 \mathrm{mg}$ of chlorphenyramine and $10 \mathrm{mg}$ diazepam orally and $100 \mathrm{mg}$ of intramuscular hydrocortisone. All injections were carried out in the operating room under fluoroscopic control by one experienced spinal surgeon (IVA) familiar with the technique. Local anesthesia supplemented by intravenous midazolam was employed and a consultant anesthetist attended. After confirmation of needle position, the involved disc was injected with 4000 picokatal units of chymopapain in $2 \mathrm{ml}$ of water. Patients were postoperatively monitored for 1 hour in the recovery. Patients were mobilized within the limit of pain and allowed to return home $4-8$ days after the procedure. 
Table 1. Chemonucleolysis Versus Disc Surgery: Preoperative Characteristics of Patients

\begin{tabular}{|c|c|c|c|}
\hline & & Injection* & Surgery* \\
\hline \multicolumn{4}{|l|}{ Demography } \\
\hline \multirow[t]{3}{*}{ Age } & Mean age (range) [yr] & $36(20-53)$ & $39(19-60)$ \\
\hline & $<40$ years & 25 & 26 \\
\hline & $>40$ years & 21 & 20 \\
\hline \multirow{2}{*}{ Sex } & Male & 27 & 28 \\
\hline & Female & 19 & 18 \\
\hline \multirow[t]{2}{*}{ Occupation } & Manual & 30 & 33 \\
\hline & Non manual & 16 & 13 \\
\hline \multirow[t]{3}{*}{ Marital status } & Single & 12 & 14 \\
\hline & Married & 31 & 30 \\
\hline & Divorced & 3 & 2 \\
\hline \multicolumn{4}{|l|}{ Co-interventions } \\
\hline \multirow[t]{5}{*}{ Painkiller } & Duration (wk) & 15 & 15 \\
\hline & NSAIDs & 19 & 21 \\
\hline & Mixed & 22 & 20 \\
\hline & opiates & 4 & 4 \\
\hline & None & 1 & 1 \\
\hline \multirow[t]{4}{*}{ Physical treatment } & Physiotherapy & 20 & $21^{\circ}$ \\
\hline & Support & 9 & 4 \\
\hline & Manipulation & 9 & 12 \\
\hline & Rest (wk) & 6 & 6 \\
\hline \multirow{3}{*}{ Pain characteristics } & Duration (wk) & 25 & 24 \\
\hline & $<6$ months & 31 & 32 \\
\hline & $>6$ months & 15 & 14 \\
\hline \multicolumn{4}{|l|}{ Clinical findings } \\
\hline \multirow[t]{5}{*}{ Root irritation } & Lumbar flexion $(\mathrm{cm})$ & 2.6 & 2.2 \\
\hline & SLR (affected leg) [] & $37^{\circ}$ & $37^{\circ}$ \\
\hline & SLR (contralateral leg) $\left[^{\circ}\right]$ & $68^{\circ}$ & $66^{\circ}$ \\
\hline & Crossed Lasegue & 22 & 24 \\
\hline & Bowstring & 31 & 35 \\
\hline \multirow[t]{4}{*}{ Root compression } & Motor weakness & 13 & 12 \\
\hline & Sensory deficit & 13 & 14 \\
\hline & Reflex deficit & 14 & 21 \\
\hline & Wasting & 1 & 2 \\
\hline \multirow[t]{4}{*}{ Radiculogram } & Root-filling defect & 43 & 46 \\
\hline & Disc bulge & 33 & 33 \\
\hline & L4-L5 level & 23 & 27 \\
\hline & L5-S1 level & 23 & 19 \\
\hline
\end{tabular}

*All expressed as number of cases unless otherwise indicated.

NSAIDs = nonsteroidal anti-inflammatory drugs; SLR = strait-leg raising.

Discectomy. Patients were medicated 1 hour before surgery with an intramuscular opiate and an antiemetic. The operation was performed under general anesthesia with the patient in the knee-chest position by a general orthopaedic surgeon. Through a fenestration or limited laminectomy, the disc prolapse was excised and the disc space cleared. Freedom and condition of the nerve root was recorded at the end of the procedure. After surgery, the patients were mobilized within the limit of pain and were discharged home by 9 or 10 days later.

\section{Results}

A total of 92 patients were randomized to receive either conventional disc surgery or chemonucleolysis. Forty-six patients in the chemonucleolysis group received the chymopapain intradiscal injection. Due to technical difficulty, injection was abandoned in one patient who underwent disc surgery 2 weeks later. Another patient, even though selected for chemonucleolysis, underwent discectomy in error. There was an $80 \%$ follow-up of patients at
6 weeks and 3 month stages and a $94 \%$ clinical follow up at 1 year. The demographic features, prior co-interventions and clinical characteristics in the two groups were comparable (Table 1).

\section{Outcome}

\section{Failure}

Nine patients in the injection group $(20.5 \%)$ and one patient in the surgical group (2.4\%) failed to improve and required surgery within 1 year. This difference was statistically significant $(P<0.02)$. The patient in the surgical group was found to have a large sequestrated disc at reexploration. One patient in the chemonucleolysis group had a small sequestrated disc fragment and three had lateral recess stenosis. No mechanical abnormality could be found in the other five patients when they were surgically explored. 
Table 2. Results for Outcome Measures

\begin{tabular}{|c|c|c|c|c|c|c|c|}
\hline & \multicolumn{3}{|c|}{ Groups (n) } & \multirow[b]{2}{*}{ I vs. S $P$ Value } & \multirow[b]{2}{*}{ Is vs. $S P$ Value } & \multirow[b]{2}{*}{ Is vs. F } & \multirow[b]{2}{*}{$S$ vs. F $P$ Value } \\
\hline & Injection & Surgery & Failed & & & & \\
\hline \multicolumn{8}{|l|}{ Disability } \\
\hline Preop & 6.2 & 6.7 & 6.7 & NS & NS & NS & NS \\
\hline 6 weeks & 3.5 & 2.9 & 6.1 & $<.2$ & NS & $<.1$ & $<.01$ \\
\hline 3 months & 3 & 2.3 & 5 & $<.1$ & $<.2$ & $<.2$ & $<.1$ \\
\hline 1 year & 2.6 & 2.8 & 4 & NS & NS & NS & NS \\
\hline \multicolumn{8}{|l|}{ Leg pain } \\
\hline Preop & 64 & 72 & 82 & NS & $<.2$ & .01 & NS \\
\hline 6 weeks & 19 & 19 & 57 & NS & NS & .03 & .01 \\
\hline 3 months & 20 & 14 & 51 & $<.05$ & $<.2$ & $<.1$ & .02 \\
\hline 1 year & 18 & 16 & 18 & NS & NS & NS & NS \\
\hline \multicolumn{8}{|l|}{ Back pain } \\
\hline Preop & 23 & 31 & 40 & NS & NS & $<.1$ & NS \\
\hline 6 weeks & 28 & 14 & 42 & $<.05$ & $<.1$ & NS & $<.1$ \\
\hline 3 months & 24 & 20 & 48 & NS & NS & NS & $<2$ \\
\hline 1 year & 23 & 22 & 22 & NS & NS & NS & NS \\
\hline \multicolumn{8}{|c|}{ Physical impairment } \\
\hline Preop & 19 & 22 & 22 & NS & $<.2$ & $<.2$ & NS \\
\hline 6 weeks & 13 & 12 & 18 & NS & NS & NS & $<.2$ \\
\hline 3 months & 13 & 7 & 21 & $<01$ & .02 & 2 & .01 \\
\hline 1 year & 10 & 10 & 17 & NS & NS & NS & $<.1$ \\
\hline \multicolumn{8}{|c|}{ Psychological score } \\
\hline Preop & 27 & 26 & 33 & NS & NS & NS & $<.2$ \\
\hline 6 weeks & 22 & 20 & 29 & NS & NS & NS & $<2$ \\
\hline 3 months & 23 & 21 & 28 & NS & NS & NS & NS \\
\hline 1 year & 21 & 20 & 23 & NS & NS & NS & NS \\
\hline
\end{tabular}

$F=$ failed injection; $I=$ injection; Is = successful injection; $N S=$ not significant; $S=$ surgery.

\section{Qualitative Outcome}

Apart from the one patient who had a discectomy after failure to inject, all other patients were examined at 6 weeks before further surgery was performed. This patient was excluded from failure group for analysis of qualitative outcome but was included for analysis of overall success. The failed chemonucleolysis group had significantly higher level of leg pain $(P<0.01)$, back pain $(P<0.05)$, and disability $(P=0.01)$ when assessed at 6 weeks, but the differences in physical impairment score $(P>0.2)$ and psychological score $(P>0.2)$ were not significant (Table 2).

There was greater back pain in the patients who had successful chemonucleolysis compared to those who had surgery $(P=0.07)$ at 6 weeks but this difference was not apparent at 3 months. The mean values for all outcome measures were higher at 3 months in the successful chemonucleolysis group and the failed injection group compared to the surgery group although many of the differences did not reach statistical significance at $5 \%$ level. There was no significant difference between the groups at the 1 year assessment (Fig 1A-F).

\section{Residual Pain}

Only $18 \%$ of chemonucleolysis patients and $31 \%$ of surgical patients were completely free of pain at 1 year. $21 \%$ of chemonucleolysis patients and $19 \%$ of disc surgery patients had residual back pain only. $61 \%$ of chemonucleolysis patients and $50 \%$ of surgical patients still had residual back pain and referred pain. Ten patients in the injection group and 14 patients in the surgical group were still taking analgesic drugs at 1 year.

\section{Neurological Outcome}

Neurological outcome at 1 year showed a few signs of residual nerve root irritation in either group. One patient in the injection group had a positive cross Lasegue's sign. Five patients in the injection group and four patients in the surgery group had positive bowstring tests. Seventeen patients in the surgery group and 12 patients in the injection group had residual neurological deficit. These findings are summarized in Table 3.

\section{Psychological Outcome}

The mean psychological score in the injection group at 1 year was 22 and in the surgical group 20. Patients with a higher preoperative psychological score $(>40)$ showed higher physical impairment score $(P=0.03)$ and disability score $(P=0.03)$, but the leg pain and back pain scores were not significantly different. Those with high preoperative psychological score had a high psychological score at 1 year. $(P<0.05)$. The psychological score was significantly higher in the injection patients who had chronic symptoms before treatment $(P=0.02)$. Manual workers had significantly higher psychological score at 1 year $(P=0.02)$. Patients with high preoperative inappropriate symptom score $(>3)$ showed higher disability score $(P=0.09)$, physical impairment score $(P=0.05)$, 


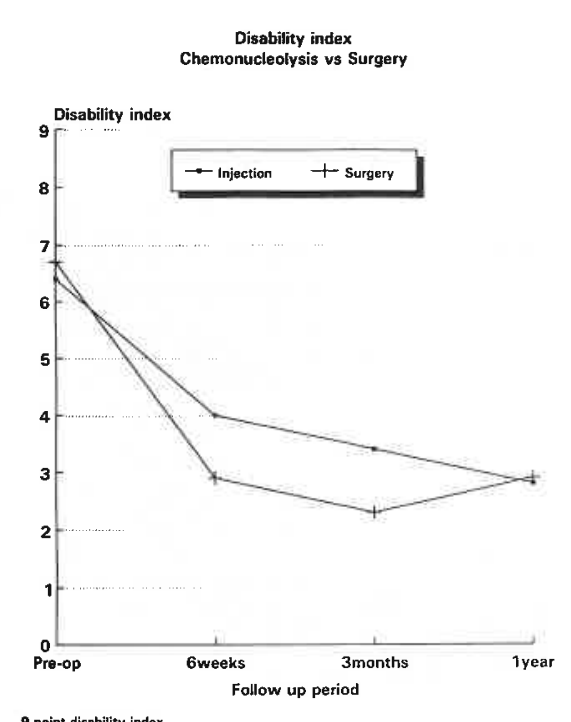

A po
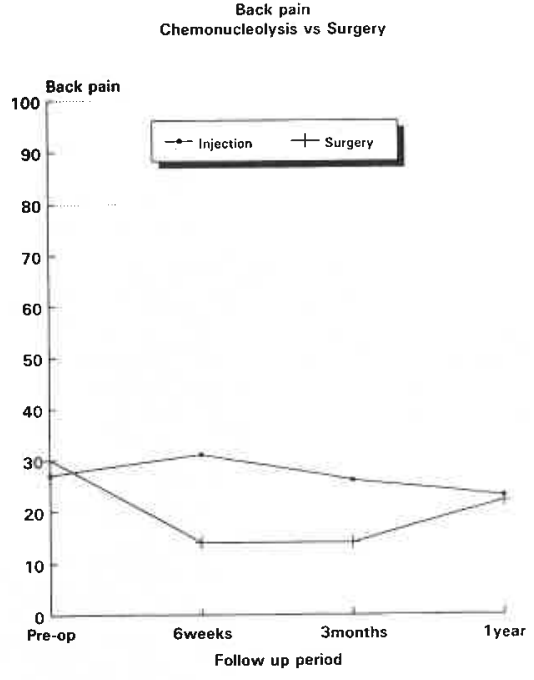

$100 \mathrm{~mm}$ Visual enalogue scale

Figure 1. Chemonucleolysis versus disc surgery: Outcome assessment scores
Physical Impairment score
Chemonucleolysis vs Surgery

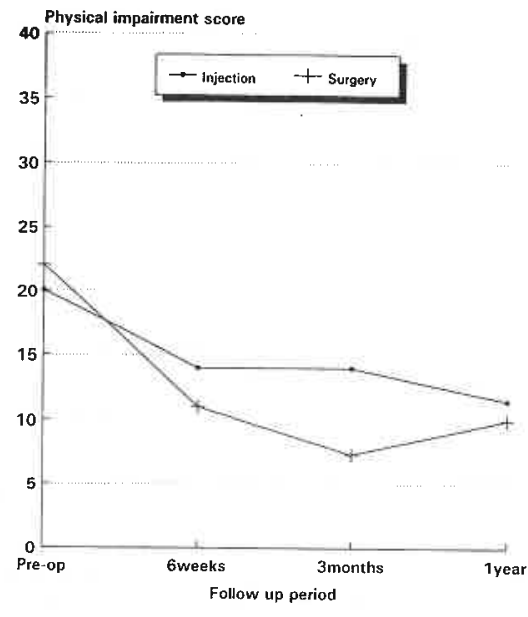

B

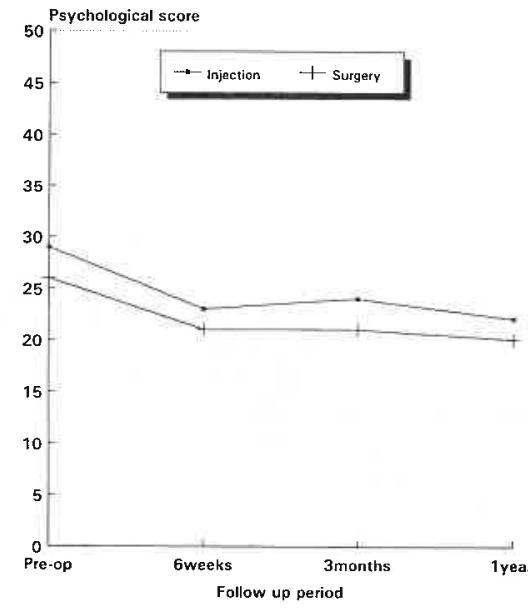

E

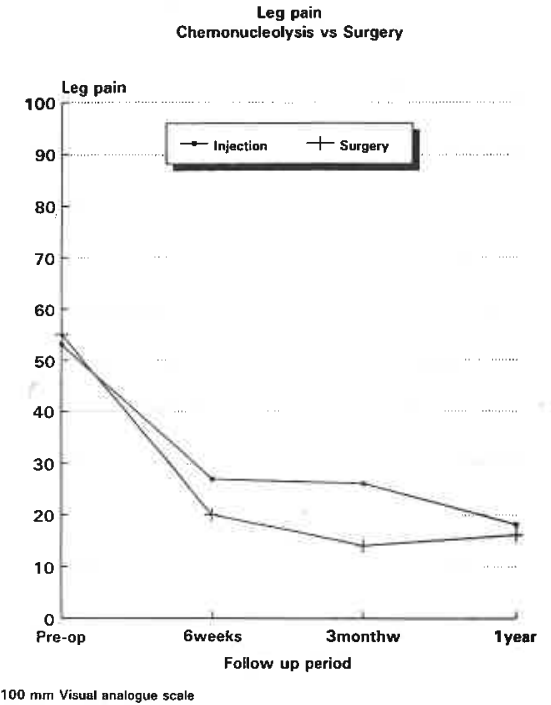

c

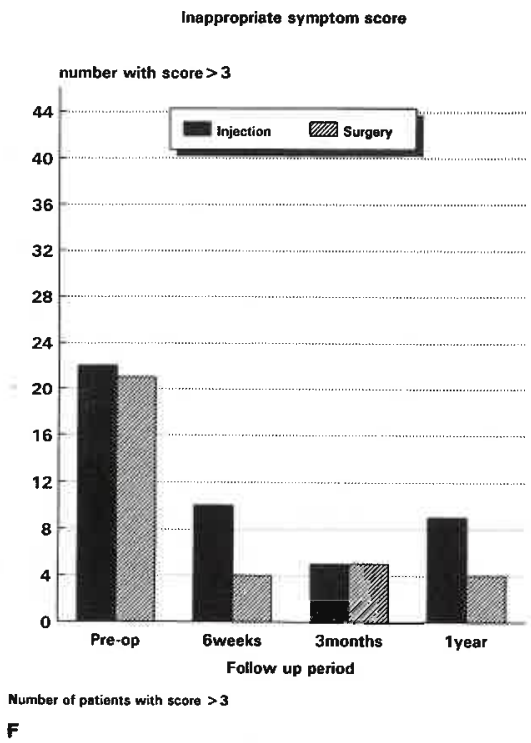

leg pain $(P=0.01)$, back pain $(P<0.01)$, and psychological score $(P=0.02)$ at 1 year. Scores were better in those with lower inappropriate sign score but the differences did not reach significant levels.

Other demographic factors such as sex, age, employment, or marital status showed no statistically significant relationship.

Table 3. Residual Neurologic Deficit at 1 Year

\begin{tabular}{lcc}
\hline & Injection $\langle \%\rangle$ & Surgery $(\%)$ \\
\hline Neurologic deficit & $12(27)$ & $17(40)$ \\
Wasting & $0(0)$ & $0(0)$ \\
Motor weakness & $4(9.1)$ & $3(7.1)$ \\
Sensory deficit & $3(6.8)$ & $8(19)$ \\
Reflex deficit & $10(23)$ & $12(29)$ \\
\hline
\end{tabular}

\section{Cost Outcome}

The preoperative costs for investigation of the patients in both groups were similar. The mean number of days of hospital stay for the chemonucleolysis patient was 21 whereas that for the surgical patient was 20. After primary treatment, the injection patient stayed in the hospital for an average of 7 days while the surgery patient stayed for 8 days. Thirteen patients in the injection group and five patients in the surgical group had to be readmitted to hospital for further treatment or rest. The average overall expense for the treatment of chemonucleolysis patient was $\$ 7500 / 4143$ whereas that for a surgical patient was $\$ 5600 / 3098$ (Table 4).

\section{Complications}

No patient suffered any serious recognized complication of their treatment in either group. One patient reported a 
Table 4. Cost Outcome

\begin{tabular}{lcc}
\hline & Injection & Surgery \\
\hline Mean hospital stay (days) & 21 & 20 \\
Mean hospital stay after treatment & 7 & 8 \\
$\quad$ (days) & 13 & 5 \\
Readmissions (n) & 3 & 3 \\
Second myelogram & 6 & 1 \\
CT scans & 2 & 0 \\
MRI scan & 9 & 1 \\
Re-exploration (no. of patients) & 397 & 108 \\
Total days (readmission) & $\mathbb{1 4 1 4 3 . 0 0}$ & $£ 3093.00$ \\
Mean cost per patient & &
\end{tabular}

$\mathrm{CT}=$ computed tomographic; magnetic resonance imaging.

transient rash 1 week after chemonucleolysis that cleared within 2 days without any treatment.

\section{Discussion}

This study was designed to conform to ideal criteria for validity and applicability for a prospective study comparing chemonucleolysis with discectomy as set out by Deyo et al. ${ }^{4}$ Validity requirements entailed randomization, minimal patient attrition less than $15 \%(6 \%$ in this study), blind outcome assessment, equivalent co-interventions, and adequate statistical power. Blind outcome assessment was not employed in this study. Instead, the assessors were independent examiners not attached to the surgical teams performing the surgery and the injections. For the study to be applicable, Deyo suggested that demographic and clinical descriptions must be adequate, inclusion and exclusion criteria must be strictly defined, and reporting outcome should include at least three out of following four: physiological, functional, psychological, and cost outcomes. ${ }^{4}$ In all these areas, this study fulfills the criteria.

Demographic and clinical characteristics and co-interventions in our study showed that, in all important variables, our treatment groups were highly comparable. The patients who were excluded because they would not comply with randomization have, to some extent, caused preselection but we have no reason to believe that this would bias the outcome, indeed it may have led to the inclusion of patients who had no preconceived ideas. The number involved in our study and the independent nature of review to 1 year permit confident conclusions to be drawn from the results.

Alphen et al. have reported the only randomized study of chemonucleolysis versus conventional disc surgery with sufficient number of patients to show that conventional disc surgery was significantly superior to chemonucleolysis. $^{25}$ Our study confirmed the findings that chemonucleolysis has inferior overall efficacy to conventional disc surgery. The reasons for chemonucleolysis failure were not clear in the majority of cases at the time of surgery. Inability to recognize technical failure in performing the procedure was not a problem because in all cases at operation, the actual disc space was empty and also the failures were not confined to the more difficult L5-S1 injection level. No simple mechanical problem could be found in the majority of patients such as unrecognized sequestration or precipitation of lateral recess stenosis by the subsequent decrease in disc height. The failures showed no predilection for demographic variables like age, occupation, or chronicity of symptoms but majority of the failed group was formed by females.

Recovery was slower in terms of improvement in leg pain in those treated by chemonucleolysis who later required surgery. However, at the end of 1 year, this subgroup of patients was not different from the other groups regarding most of the outcome measures except for physical impairment score, which was still slightly higher in the failed group $(P=0.1)$. The recovery in terms of relief of pain, improvement in disability and physical impairment was not significantly different in the successful chemonucleolysis group and surgical group, but the rate of improvement during the first 3 months after treatment was better in the surgical group.

Patients left the hospital 1 day earlier, on average, after chemonucleolysis than discectomy. However, the total cost of treatment with chemonucleolysis proved to be greater than that for discectomy in the end. This finding is in agreement with that of Norton et al. ${ }^{19}$ but at variance with others. ${ }^{18,20}$

Significant back pain and back muscle spasm occurred in more than $50 \%$ of patients treated with chemonucleolysis. This took 3-7 days (in some cases even longer) to settle. Consequently there was no evidence that minimal nature of surgery hastens recovery, indeed in the $20 \%$ of patients who failed to respond to chemonucleolysis, recovery was significantly hindered because of not resorting to disc surgery in the first instance. There was only slight improvement in psychological score in both groups with successive follow ups and the groups did not differ in their rate of improvement with time except in the primary failure group. This suggests that the treatment has no intrinsic psychological effect on the patient and their psychological profile merely reflected their state of well being at that time. The absence of significant difference in pain outcome between those with higher and lower psychological scores is at variance with observation of other authors. ${ }^{31,33}$ However, the final outcome in patients with high inappropriate symptom score was poorer. In this study, inappropriate symptom score was more predictive of outcome than psychological score.

\section{Conclusion}

Chemonucleolysis as a minimally invasive technique produces short-term inferior results and offers no advantage over conventional discectomy. The surgical findings at operation inadequately explain the cause of failure. A 
subgroup of patients (failure group) is denied the opportunity to rehabilitate from their pain and disability quickly.

\section{Acknowledgments}

The authors wish to thank Mrs. Sharon Rogers and Miss Lily McGuffin for their help with the conduction of this trial.

\section{References}

1. Brown MD, Tompkins JS: Pain response post-chemonucleolysis or disc excision. Spine 14(3):321-326, 1989

2. Crawshaw C, Fraser AM, Merriam WF, Mulholland RC, Webb JK: A comparison of surgery and chemonucleolysis in the treatment of sciatica. Spine 9(2):195-198, 1984

3. Dabezius EJ, Brunet M: Chemonucleolysis versus Laminectomy. Orthopaedics 1:26-29, 1978

4. Deyo RA: Chymopapain for herniated intervertebral disc: A methodological analysis and an agenda for future research. Spine 9:474-478, 1984

5. Ejeskar A, Nachemson A, Herberts P, Lysell E, Andersson G, Irstam L, Peterson L-E: Surgery versus Chemonucleolysis for herniated lumbar discs. Clin Orthop 174:236-242, 1983

6. Feffer HL: Treatment of low back and sciatic pain by the injection of hydrocortisone into degenerated intervertebral discs. JBJS 38A:585-592, 1956

7. Fraser RD: Chymopapain for treatment of intervertebral disc herniation. Spine 7(6):608-612, 1982

8. Goldstein G, Gross PF: The treatment of herniated disc in Australia: Cost and benefits of intradiscal injection of chymopapain and surgery. Australian Family Physician 14(11):1179_ 1190,1985

9. Javid MJ, Nordby EJ, Ford LT, et al: Safety and efficacy of chymopapain in herniated nucleus pulposus with sciatica. JAMA 249(18):2489-2494, 1983

10. Kambin P: Percutaneous posterolateral discectomy. Clin Orthop 223:145-154, 1987

11. Leavitt F, Garron DC, Whisler WW, D'Angelo CM: A comparison of patients treated by chymopapain and laminectomy for low back pain using a multidimensional pain scale. Clin Orthop 146:136-143, 1980

12. Macnab IM, McCulloch JA: Sciatica and Chymopapain. Baltimore, Williams \& Wilkins, 1983, pp 182-196

13. Main CJ: Modified Somatic Perception Questionnaire (MSPQ). J Psychosomatic Res. 1983; 27(6):503-514

14. Maroon JC, Abla A: Microdiscectomy versus chemonucleolysis. Neurosurgery 16(5):644-649, 1985

15. McCulloch JA: Chemonucleolysis: Experience with 2000 cases. Clin Orthop 146:128-135, 1980

16. Mixter WJ, Barr JS: Rupture of the intervertebral disc with involvement of the spinal canal. New Eng J Med 211(5):208215,1934

17. Nordby EJ, Lucas GL: A comparative analysis of lumbar disc disease treated by laminectomy or chemonucleolysis. Clin Orthop 90:119-129, 1973

18. Nordby EJ: A comparison of discectomy and chemonucleolysis. Clin Orthop 200:279-283, 1983
19. Norton WL: Chemonucleolysis versus surgical discectomy. Spine 11(5):440-443, 1986

20. Ramirez LF, Javid MJ: Cost effectiveness of chemonucleolysis versus laminectomy in the treatment of herniated nucleus pulposus. Spine 10(4):363-367, 1985

21. Schwartz D, Ulstrom C, Chowins J, Kuslich SD: Lumbar disc herniation: How does the choice of treatment affect the cost of care? Minnisota Medicine 71:489-491, 1988

22. Smith L: Enzyme dissolution of nucleus pulposus. Nature 4887:1311-1312, 1963

23. Spangforte E: Lumbar disc herniation: A computer aided analysis of 2504 operations. Acta Orthop Scand Suppl 142:171,1972

24. Tregoning GD, Transfeldt EE, McCulloch JA, Macnab I, Nachemson A: Chymopapain versus Conventional surgery for lumbar disc herniation. Ten year results of treatment. JBJS 73-B (3):481-486, 1991

25. Van Alphen HAM, Braakman R, Bezemer D, Broere G, Berfello W. Chemonucleolysis versus discectomy: a randomised multicentre trial. J. Neurosurg 70:869-875, 1989

26. Waddell G, Main CJ: Assessment of severity in low back disorders. Spine 9(2):204-208, 1984

27. Waddell G, McCulloch JA, Kummel E, Venner RM: Nonorganic physical signs in low back pain. Spine 5(2):117_ 125,1980

28. Waddell G, Main CJ, Morris EW, Paola MD, Gray ICM: Chronic low back pain, psychological distress and illness behaviour. Spine 9(2):209-213, 1984

29. Waddell G: Clinical assessment of lumbar impairment. Clin Orthop 221:110-120, 1987

30. Watts C, Hutchinson G, Stern J, Clark K: A comparison of intervertebral disc disease treatment by chymopapain injection and open surgery. J Neurosurgery 42:397-400, 1975

31. Weber H: Lumbar disc herniation: A controlled prospective study with ten years of observation. Spine 8(2):131-140, 1983 32. Weinstein J, Spratt KF, Lehmann T, McNeill T, Hejna W: Lumbar disc herniation: A comparison of results of chemonucleolysis.. JBJS 68A(1):43-54, 1986

33. Wiltse LL, Rocchio PD: Pre-operative psychological tests as predictors of success of chemonucleolysis. JBJS $58 \mathrm{~A}(4): 478-$ 483,1975

34. Zeiger Jr HE: Comparison of chemonucleolysis and microsurgical discectomy for the treatment of herniated lumbar disc. Spine 12(8):796-799, 1987

35. Zung WWK: A self-rating depression scale. Archives of Gen Psychiatry 12:63-70, 1965

Address reprint requests to

K. P. Muralikuttan, FRCS, MMedSc,
Department of Orthopaedic Surgery
Queen's University of Belfast
Musgrave Park Hospital
Belfast BT9 7JB
Northern Ireland

